\section{Kidney \\ Blood Pressure Research}

DOI: $10.1159 / 000489620$

Published online: 8 May, 2018

Accepted: 26 April, 2018

This article is licensed under the Creative Commons Attribution-NonCommercial-NoDerivatives 4.0 International License (CC BY-NC-ND) (http://www.kargercom/Services/OpenAccessLicense). Usage and distribution for commercial purposes as well as any distribution of modified material requires written permission.

\title{
Protective Effect of Nicotinamide Adenine Dinucleotide Phosphate on Renal Ischemia- Reperfusion Injury
}

\author{
Xiao-fen Weng ${ }^{\mathrm{a}, \mathrm{b}}$ Song-tao Lid ${ }^{\mathrm{d}}$ Qi Song ${ }^{\mathrm{a}}$ Qi Zhu ${ }^{\mathrm{c}}$ Dan-dan Song ${ }^{\mathrm{c}}$ \\ Zheng-hong Qinc Yan Xie ${ }^{a}$
}

aThe First Affiliated Hospital of Soochow University, Suzhou, Jiangsu, 'bSuzhou Municipal Hospital, Suzhou, Jiangsu, 'Department of Pharmacology and Laboratory of Aging and Nervous Diseases, Soochow University School of Medicine, Suzhou, Jiangsu, dPeople's Hospital of Huangjing, Suzhou, Jiangsu, China

\section{Key Words}

Renal ischemia reperfusion injury - NADPH • Oxidative stress - Apoptosis - Inflammation • HK-2 cells

\begin{abstract}
Background/Aims: Renal ischemia-reperfusion injury (IRI) is a common consequence of acute kidney injury. Nicotinamide adenine dinucleotide phosphate (NADPH), which is derived from the pentose phosphate pathway, is essential for the proper functioning of essential redox and antioxidant defense systems. Previous studies have indicated that NADPH is responsible for protecting the brain from ischemic injury. The goal of this study was to analyze the protective function of NADPH in renal IRI. Methods: The IRI animal model was generated through a midline laparotomy surgery that clamped both sides of the renal pedicles for $40 \mathrm{~min}$ to induce renal ischemia. The in vitro model was generated by removing oxygen and glucose from human kidney epithelial cells (HK-2 cells), followed by reoxygenation to imitate IRI. Renal function and histopathological changes were observed and evaluated. Additionally, malondialdehyde and glutathione levels were determined in renal tissue homogenate as indicators of oxidative stress. ROS production in cells was determined by DHE staining. Protein biomarker expression was evaluated by western blot, apoptosis was analyzed by TUNEL staining, and p65 nuclear translocation was visualized by immunofluorescence. Results: Our data indicated that NADPH safeguarded the kidneys from histological and functional damage, and significantly reduce cell injury along with preventing potential increases in blood urea nitrogen and creatinine levels. Furthermore, we observed that NADPH increased glutathione levels, while reducing levels of malondialdehyde and reactive oxygen species. Additionally, our results suggested
\end{abstract}




\section{Kidney Blood Pressure Research}

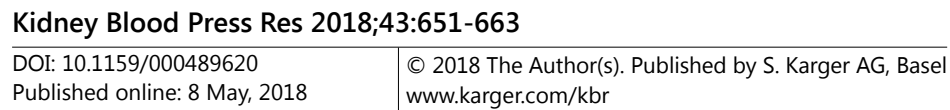

Weng et al.: Protective Effect of NAPDH on Renal IRI

that NADPH treatment may alleviate IRI-induced apoptosis and inflammation. Conclusion: $\mathrm{NADPH}$ treatment may protect against renal IRI and should be further developed as a new treatment for acute kidney injury.

\section{Introduction}

Acute kidney injury (AKI) is an abrupt and debilitating decline in kidney function that can be fatal in many cases [1]. AKI occurs in different clinical situations, such as patients who have undergone kidney transplantation or heart surgery, or have hypotension, renal artery stenosis or sepsis [2]. Renal ischemia-reperfusion injury (IRI) can cause AKI, and there are no viable treatment options available [1,3]. The detrimental impacts of renal IRI are the consequence of interrelated and complex events that are not fully understood [3]. Previous studies have suggested that apoptosis, inflammation and oxidative stress are related to renal IRI $[2,4-6]$. In cases where ischemic tissues experience reperfusion, reactive oxygen species (ROS) are responsible for increasing oxidative stress [6-8], the expression of pro-apoptotic mediators [9,10], and inflammatory cytokines [11-13].

TP53-induced glycolysis and apoptosis regulator (TIGAR) was reported to inhibit glycolysis and increase flux through the pentose phosphate pathway (PPP) [14]. A previous study indicated that TIGAR regulated glycolysis in ischemic kidney proximal tubules [15] and was neuroprotective against ischemic brain injury by increasing flux through the PPP [16]. The main function of the PPP is to generate nicotinamide adenine dinucleotide phosphate (NADPH), which works as a coenzyme in a wide range of oxidation-reduction reactions. NADPH is also essential for maintaining levels of reduced glutathione (GSH), which is a significant contributor to endogenous antioxidant processes [17-20]. Additionally, NADPH provides the energy to shuttle isocitrate into the mitochondria to develop cellular energy homeostasis. It was previously demonstrated that exogenous NADPH could protect neurons from IRI [18]. Thus, we hypothesized that NADPH could also prevent IRI-induced kidney damage. The objective of this study is to evaluate the effects of exogenous NADPH on renal IRI and other renal functions.

\section{Materials and Methods}

\section{Animals}

This study was carried out in accordance with the Guide for the Care and Use of Laboratory Animals (NIH, 1985) and with the approval from the Ethical Committee of Soochow University. Based on the previous study, 5 and $1 \mathrm{mg} / \mathrm{kg}$ NADPH (Roche, Basel, Switzerland) doses were selected. This study used 32 ICR male mice (age range: 8-10 weeks; weight range: 25-28 g) purchased from Shanghai Slack Laboratory Animal Ltd. (Shanghai, China). The mice were randomly divided into four groups: (1) I/R group, (2) sham-operated group, (3) I/R + $5 \mathrm{mg} / \mathrm{kg}$ NADPH and (4) I/R + $1 \mathrm{mg} / \mathrm{kg}$ NADPH. Saline solution was given to the animals in the I/R and sham-operated groups. NADPH dissolved in saline was given through tail vein injections both 24 and $1 \mathrm{~h}$ before laparotomy, and $1 \mathrm{~h}$ after reperfusion. All mice were given anesthesia along with an intrapulmonary injection of $4 \%$ chloral hydrate. A heating lamp was used to keep a $37^{\circ} \mathrm{C}$-body temperature in the mice. All mice were laid in a supine position before undergoing surgical procedures. The animal's abdomen was shaved, and the exposed skin was prepared aseptically. For mice in the IRI groups, both sides of the renal pedicles were divided and clamped for $40 \mathrm{~min}$ followed by 24 -h reperfusion. The sham-operated group followed the same surgical procedures except ischemia. After that, all mice were given anesthesia. Kidney samples were later taken from all groups for biochemical and histopathological analyses.

Cell Culture and the Oxygen-Glucose Deprivation/Reoxygenation Protocol

The normal human kidney epithelial cell line HK-2 was purchased from the American Type Culture Collection (Manassas, VA, USA) and was cultured in Dulbecco's modified Eagle's medium-F12 (DMEM-F12) 


\section{Kidney Blood Pressure Research}

\begin{tabular}{|c|c|}
\hline Kidney Blood Press Res & $: 651-663$ \\
\hline $\begin{array}{l}\text { DOI: } 10.1159 / 000489620 \\
\text { Published online: 8 May, } 2018\end{array}$ & $\begin{array}{l}\text { ( } 2018 \text { The Author(s). Published by S. Karger AG, Basel } \\
\text { www.karger.com/kbr }\end{array}$ \\
\hline
\end{tabular}

Weng et al.: Protective Effect of NAPDH on Renal IRI

(Gibco/Thermo Fisher, Waltham, MA, USA) supplemented with 10\% fetal bovine serum (Gibco/Thermo Fisher, Waltham, MA, USA) and $100 \mathrm{U} / \mathrm{ml}$ penicillin/streptomycin (North China Pharmaceutical Co., Ltd., Shijiazhuang, China). A humidified incubator $\left(95 \%\right.$ air with $\left.5 \% \mathrm{CO}_{2}\right)$ was used to store the cells at $37^{\circ} \mathrm{C}$. One day prior to experimentation, $5 \times 10^{3}$ or $5 \times 10^{4}$ cells per well were plated into 96 - or 24 -well tissue culture plates, respectively.

For oxygen-glucose deprivation studies, HK-2 cells were placed in an MC-101 chamber (BillupsRothenberg Inc., San Diego, CA, USA) filled with $95 \% \mathrm{~N}_{2}$ and $5 \% \mathrm{CO}_{2}$ at $37^{\circ}$, incubated with glucose-free Hank's balanced salt solution (HBSS; $151 \mathrm{mmol} / \mathrm{L} \mathrm{NaCl}, 3.5 \mathrm{mmol} / \mathrm{L} \mathrm{CaCl}_{2}, 4.8 \mathrm{mmol} / \mathrm{L} \mathrm{KCl}, 44 \mathrm{mmol} / \mathrm{L}$ HEPES, $7.8 \mathrm{mmol} / \mathrm{L} \mathrm{NaHCO}{ }_{3}, 1 \mathrm{mmol} / \mathrm{L} \mathrm{KH}_{2} \mathrm{CO}_{3}$ and $2.7 \mathrm{mmol} / \mathrm{L} \mathrm{MgSO}{ }_{4}, \mathrm{pH} 7.4$ ). After 8 -h oxygen-glucose deprivation, the cells were rinsed three times with phosphate-buffered saline (PBS). The culture medium was replaced with normal DMEM-F12, and cells were cultured under normal conditions for $24 \mathrm{~h}$ for reoxygenation. Control cells were incubated in HBSS containing $3 \mathrm{mM}$ D-glucose and were maintained under normal culture conditions for the same duration.

\section{NADPH Treatment}

HK-2 cells were washed with PBS three times, and then incubated with DMEM-F12 containing different NADPH doses $(6.25,12.5$ and $25 \mu \mathrm{mol} / \mathrm{L})$ for $4 \mathrm{~h}$, followed by the 8-h oxygen-glucose deprivation protocol in HBSS with the addition of the same NADPH doses. Then, the cells were maintained under normal conditions for $24 \mathrm{~h}$ for reoxygenation in DMEM-F12 with NADPH. Control cells were held in normal conditions for the duration of the experiment.

\section{Renal Function}

Blood samples were extracted from the ventricular vein plexus and centrifuged at $4000 \mathrm{rpm}$ for 10 $\mathrm{min}$. The supernatant was analyzed to identify serum levels of creatine ( $\mathrm{Cr}$ ) and blood urea nitrogen (BUN) using assay kits from Nanjing Jiancheng Bioengineering Institute (C0011-2 and C0013-2, respectively; Nanjing, China). The weight of both kidneys was taken, and the ratio of kidney weight to total body weight (KW/BW) was calculated.

\section{Malondialdehyde (MDA) and GSH Measurements}

Renal MDA and GSH levels were measured using GSH assay kits (BioAssay Systems Hayward, CA, USA) and MDA assay kits (A003-1C; Nanjing Jiancheng Bioengineering Institute, Nanjing, China) following the respective manufacturers' protocols.

\section{Renal Histopathology}

Kidney tissues were embedded in paraffin and immersed in phosphate-buffered $4 \%$ formalin (pH 7.4) for $24 \mathrm{~h}$ and used for periodic acid-Schiff (PAS) staining. Afterwards, the sections were cut into 5 - $\mu \mathrm{m}$ slices. The PAS-stained sections were used to evaluate tubular injury with a high-resolution digital camera system and an Olympus light microscope (Olympus, Tokyo, Japan). The severity of tubular injury was assessed by a renal pathologist who was unaware of the different treatments and experimental history of the mice. Tubular necrosis was evaluated in a semi-quantitative manner by determining the percentage of tubules in the external medulla area where epithelial necrosis, loss of the brush border, cast formation, and/or tubular dilation were observed. A five-point scale was used: 0 , normal kidney; $1,<25 \%$ tubular necrosis; 2 , 25\%-50\% tubular necrosis; 3, 50\%-75\% tubular necrosis; and 4, >75\% tubular necrosis [5].

\section{Cell Viability Assay}

The viability of cultured HK- 2 cells was analyzed using Cell Counting Kit-8 (CCK-8, Dorado Laboratories, Kumamoto, Japan). The cells were grown in 96-well culture plates, and then $10 \mu \mathrm{L}$ of CCK-8 and $100 \mu \mathrm{L}$ of medium were added per well and incubated with the cells at $37^{\circ} \mathrm{C}$ for $2 \mathrm{~h}$. After $24 \mathrm{~h}$, the oxygen-glucose deprivation/reperfusion protocol was performed, and a microplate reader (ELX 800, BioTek, Winooski, VT, USA) was used to measure optical densities at $450 \mathrm{~nm}$. 


\section{Kidney Blood Pressure Research}

Weng et al.: Protective Effect of NAPDH on Renal IRI

\section{Dehydrogenate (DHE) Fluorescence}

HK-2 cells were incubated with DHE (1:2000; Beyotime, Nanjing, China) for $20 \mathrm{~min}$ at $37^{\circ} \mathrm{C}$, and then were rinsed in PBS for ROS detection. A fluorescence microscope (Olympus, Tokyo, Japan) and a laserscanning confocal microscope (Carl Zeiss, Oberkochen, Germany) were used to observe DHE fluorescence. The number of positive cells marked with DHE staining per $\mathrm{mm}^{2}$ was counted in each group.

\section{Hoechst Staining}

Cells were fixed with $4 \%$ paraformaldehyde for $30 \mathrm{~min}$ at room temperature after different treatments. Afterwards, the cells were incubated with Hoechst 33342 (C0003; Beyotime, Nanjing, China) at $37^{\circ} \mathrm{C}$ for 20 min. Hoechst staining was imaged with a fluorescence microscope (Olympus) after washing the cells in PBS.

Terminal Deoxynucleotidyl Transferase dUTP Nick-end labeling (TUNEL) Assay

Morphological detection of apoptotic cells was carried out using TUNEL assays (Cat. No. 11684817910; Roche) based on the manufacturer's directions. DAPI staining was used to label all nuclei, and TUNELpositive cells were analyzed using a fluorescence microscope.

\section{Immunofluorescence}

Immunofluorescence was carried out using previously described protocols [21]. Briefly, HK-2 cells were fixed with $4 \%$ paraformaldehyde, permeabilized with $0.1 \%$ Triton X-100 for 10 min, blocked in $1 \%$ normal bovine serum albumen for $1 \mathrm{~h}$ at room temperature, rinsed with PBS three times, and incubated overnight with anti-p65 antibody (1:500; Abcam, Cambridge, UK). The following day, the cells were washed and incubated with AlexaFluor594-labeled anti-rabbit IgG (1:400; Jackson Immuno Research, West Grove, PA, USA) for $1 \mathrm{~h}$ at $37^{\circ} \mathrm{C}$. Nuclei were stained with DAPI (1:10000; Beyotime, Nanjing, China). p65 nuclear translocation rates were measured using a laser-scanning confocal microscope (Carl Zeiss).

\section{Western Blot Analysis}

Kidney tissues were homogenized and total protein samples were extracted in cold lysis buffer (10 mmol/L Tris-HCl [pH 7.4], $150 \mathrm{mmol} / \mathrm{L} \mathrm{NaCl}, 5 \mathrm{mmol} / \mathrm{L}$ acetic acid, 0.1\% SDS, 1\% sodium deoxycholate and $1 \%$ Triton X-100) containing one protease inhibitor cocktail tablet (Roche, Basel, Switzerland) per 10 mL. SDS-PAGE was used to separate equal amounts $(30-50 \mu \mathrm{g})$ of protein, which were later transferred to nitrocellulose membranes. The membranes were probed with the following antibodies at $4{ }^{\circ} \mathrm{C}$ overnight: rabbit anti-Cox-2 (1:1000; Santa Cruz Biotechnology, Dallas, TX, USA), rabbit anti-IкB- $\alpha$ (1:1000; Santa Cruz Biotechnology, Dallas, TX, USA), mouse anti-Bcl-2 (1:1000; Santa Cruz Biotechnology), rabbit-anti-Bax (1:200; Cell Signaling Technology, Danvers, MA, USA), rabbit anti-Cleaved-Caspase3 (1:1000; Cell Signaling Technology, Danvers, MA, USA), and mouse anti- $\beta$-actin (1:5000; LI-COR, Lincoln, NE, USA). The following day, the membranes were washed and incubated with the appropriate anti-rabbit or anti-mouse secondary antibodies (1:10000; LI-COR) for $2 \mathrm{~h}$ at room temperature. Immunoreactive bands were revealed by an Odyssey two-color infrared imaging system (LI-COR) and were analyzed using ImageJ (NIH, Bethesda, MD, USA), with protein levels normalized to $\beta$-actin.

\section{Statistical Analysis}

Data are shown as mean \pm SD; one-way ANOVA was used to identify differences among the groups. The Newman-Keuls test was applied for post-hoc analyses.

\section{Results}

\section{NADPH Treatment Improves Renal IRI in Mice}

PAS staining indicated that the kidneys of the sham-operated group showed no damaging pathological deformities, tubules and glomeruli were all structurally intact (Fig.1A $)$. Conversely, kidney tissues from the IRI group showed overt swelling in the renal tubular cells along with increased inflammatory cells and coagulating necrosis. Furthermore, the disappearance of the brush border and vacuole degeneration were also observed (Fig. $\left.1 \mathrm{~A}_{2}\right)$. 


\section{Kidney Blood Pressure Research}

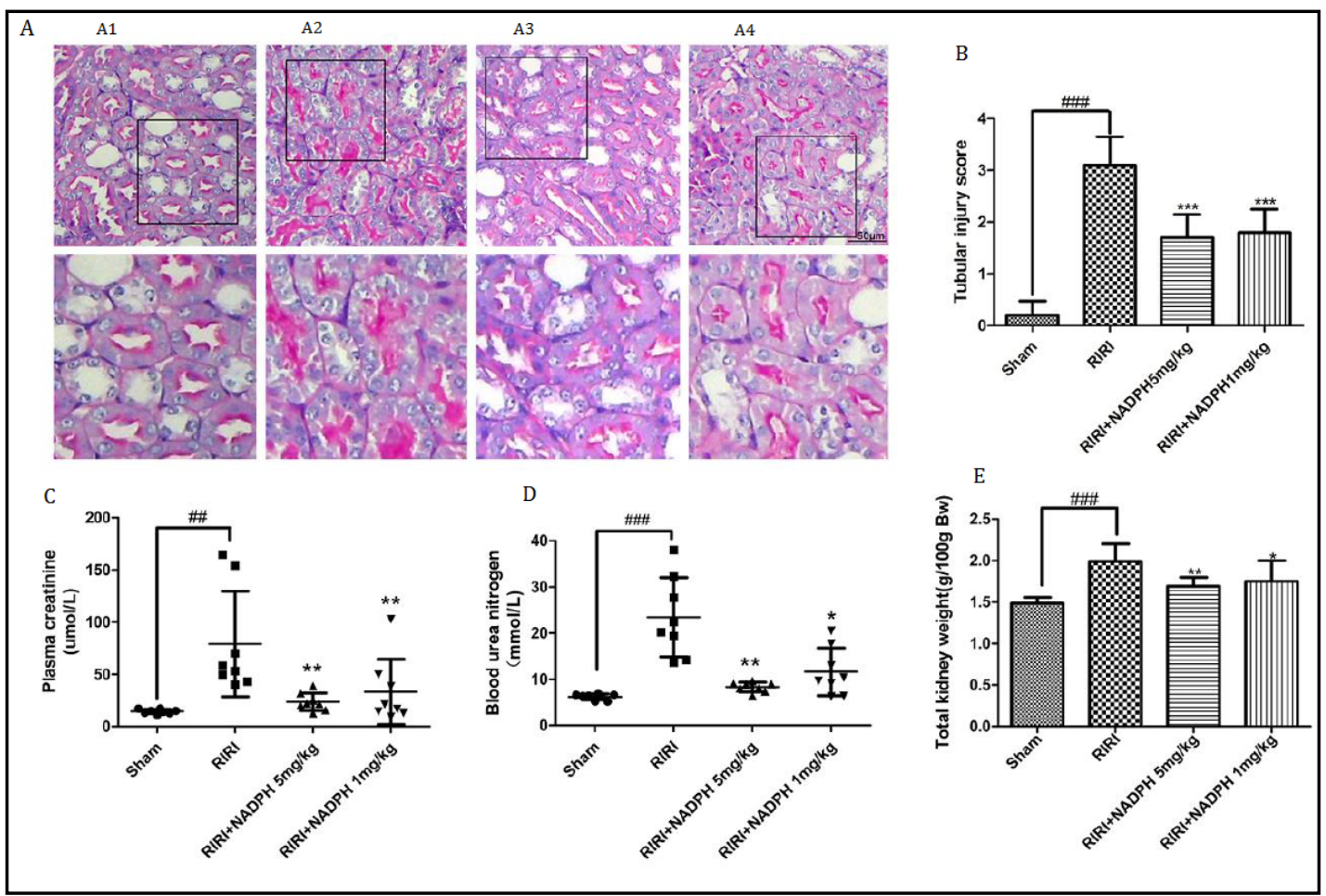

Fig. 1. NADPH Improves Renal IRI in Mice. Periodic acid-Schiff (PAS) staining shows pathological changes $24 \mathrm{~h}$ after IRI. $\mathrm{A}_{1}, \mathrm{~A}_{2}, \mathrm{~A}_{3}$ and $\mathrm{A}_{4}$ are representative images of PAS-stained kidney sections of the Sham, RIRI, RIRI+5 mg/kg NADPH and RIRI+1 mg/kg NADPH; magnification: 200×; B was the semi-quantification of tubular injury. BUN and $\mathrm{Cr}$ levels were detected using venous blood samples. NADPH supplementations caused reductions in $\mathrm{Cr}(\mathrm{C})$, BUN (D), and the KW/BW ratio (E). Bar represents mean $\pm \mathrm{SD} ; \mathrm{n}=8$; \#\#\# $<<0.001$, \#\# $\mathrm{p}<0.01$ vs the Sham group; ${ }^{* *} \mathrm{p}<0.01,{ }^{*} \mathrm{p}<0.05$ vs the RIRI group.

The mice receiving 1 or $5 \mathrm{mg} / \mathrm{kg}$ NADPH both showed a marked reduction in renal histopathology injuries (Fig. $1 \mathrm{~A}_{3}$ and $\mathrm{A}_{4}$ ). Semiquantitative analysis showed that kidneys from NADPH-treated groups displayed reductions in tubular damage when compared with kidneys of sham-operated group (Fig.1B). Assay kits were used to evaluate serum markers of kidney injury. Compared with the sham-operated group, the serum Cr (Fig.1C), BUN (Fig.1D), and the KW/BW ratio (Fig.1E) in the IRI group were elevated. These markers were significantly restored by NADPH treatment 24-h after reperfusion compared with the RIRI group.

\section{NADPH Protects HK2 Cells from Oxygen-Glucose Deprivation/Reperfusion Injury}

HK-2 cells were deprived of oxygen and glucose followed by reoxygenation to imitate renal IRI in vitro. The CCK-8 assay showed that proliferation was not seen in HK-2 cells treated with $6.25,12.5$ or $25 \mu \mathrm{mol} / \mathrm{L}$ NADPH (Fig.2A). These data further indicated that $6.25 \mu \mathrm{mol} / \mathrm{L}$ NADPH treatment dramatically increased cell viability for cells that underwent 8 h-oxygenglucose deprivation and $24 \mathrm{~h}$ reperfusion, which confirmed that NADPH had a protective influence on HK-2 cells from oxygen-glucose deprivation/reperfusion-induced injury.

\section{NADPH Attenuates Oxidative Stress In vivo and In vitro}

IRI is related to increased ROS production; therefore, the radioprotective effects of NADPH were analyzed to determine if they were attributable to reduced ROS levels. The quantifications (Fig.2B) and images (Fig.2C) of DHE fluorescence showed increased ROS levels in HK-2 cells $1 \mathrm{~h}$ after reperfusion. After oxygen-glucose deprivation, cells from NADPH treatment group showed decreased ROS levels compared with untreated group. While GSH 


\section{Kidney Blood Pressure Research}

Fig. 2. NADPH Protects from OxygenGlucose Deprivation/ Reperfusion Injury and Attenuates Oxidative Stress In Vitro. HK-2 cells received different doses of NADPH with or without oxygenglucose deprivation. In the oxygen-glucose deprivation groups, cells were subjected to oxygen-glucose deprivation for 8 $h$, and reperfusion injury was achieved by resupplying glucose and oxygen for $24 \mathrm{~h}$. Viability was detected using the CCK-8 assay (A), and quantifications

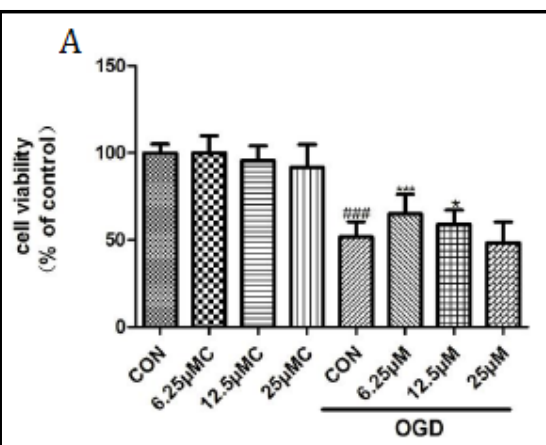

C
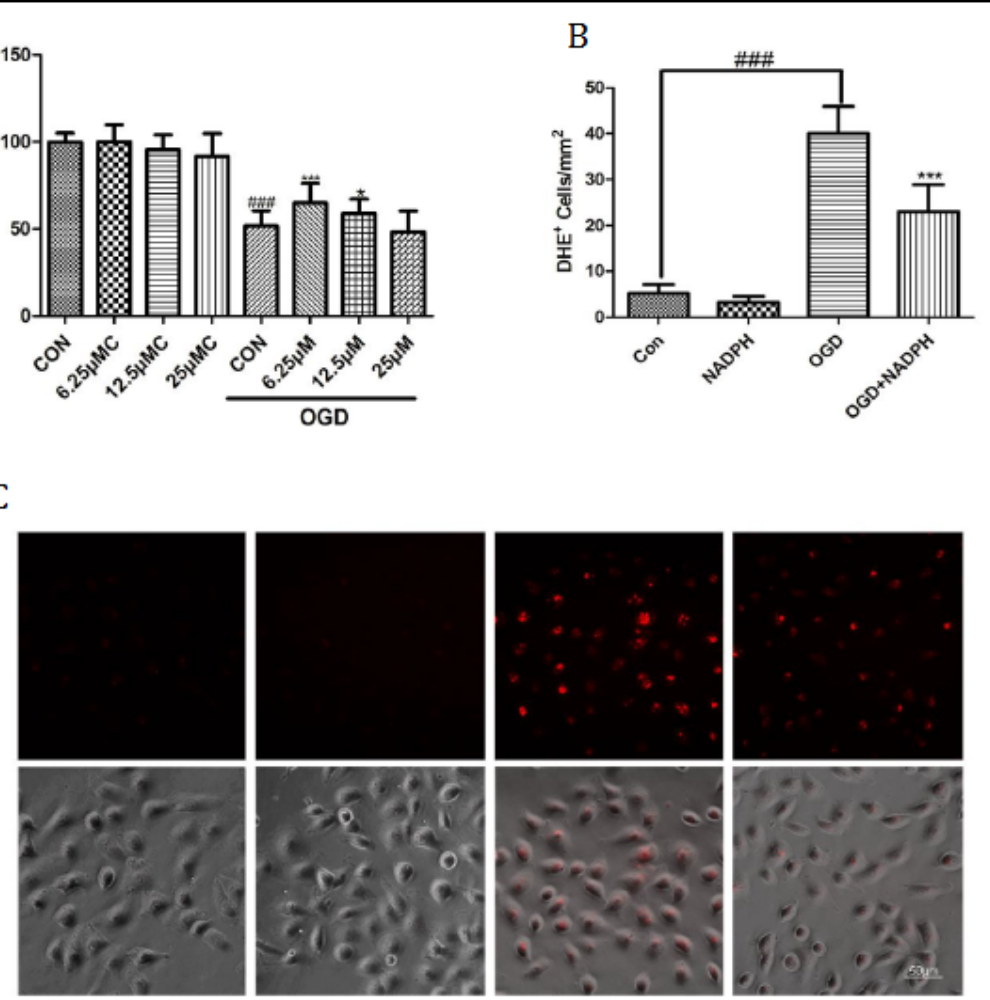

and representative

photographs (C) of

DHE fluorescence showed ROS levels in HK-2 cells $1 \mathrm{~h}$ after reperfusion. Scale bar: $50 \mu \mathrm{m}$; Bar represents

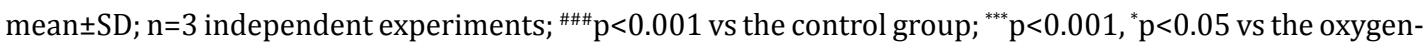
glucose deprivation control group.

Fig. 3. NADPH

A t t e $n$ a t e $s$ Oxidative Stress In Vivo. Mice in the different groups received different treatments, and kidney tissues were taken after the mice were sacrificed. GSH and MDA levels were measured in kidney lysates (A

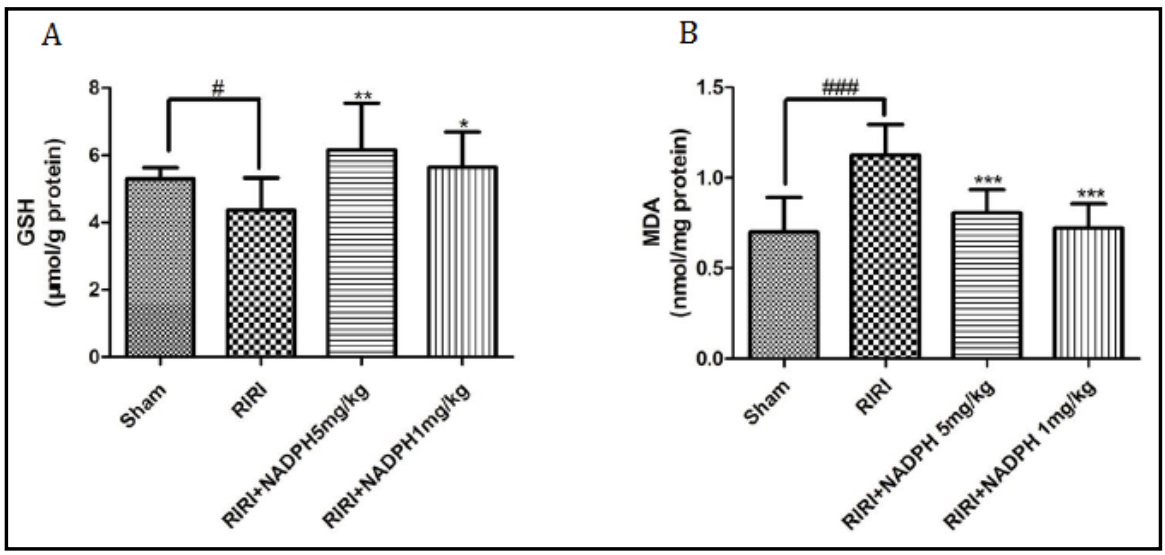
and $\mathrm{B}$, respectively). Bar represents mean $\pm \mathrm{SD} ; \mathrm{n}=8$; ${ }^{\# \# \#} \mathrm{p}<0.001,{ }^{\#} \mathrm{p}<0.05$ vs the Sham group; ${ }^{* * *} \mathrm{p}<0.001,{ }^{* *}$ $\mathrm{p}<0.01,{ }^{*} \mathrm{p}<0.05$ vs the RIRI group.

levels (Fig.3A) were markedly decreased, renal MDA levels (Fig.3B) in the renal IRI group were obviously increased compared with the sham group. Both phenotypes were reversed by NADPH treatment, suggesting that increased NADPH levels are important for redox homeostasis and can mitigate ROS production. ROS production in HK-2 cells was determined by DHE staining. These results indicated that NADPH reduced IRI-induced oxidative stress in vitro and in vivo. 


\section{Kidney Blood Pressure Research}

NADPH Blocks Apoptosis In vivo and In vitro

NADPH has been shown to reduce ROS and attenuate renal IRI through its anti-apoptotic activity. Bax and Bcl-2 play a vital role in the mitochondrial apoptosis pathway and caspase- 3 is the main apoptosis executor. Compared with controls, renal IRI increased Bax (Fig.4A and $\mathrm{A}_{2}$ ) and Bcl-2 (Fig.4B $\mathrm{B}_{1}$ and $\mathrm{B}_{2}$ ) expression, which was reversed by NADPH treatment. Consistently, IRI increased cleaved Caspase-3 levels, which were also reduced by NADPH treatment (Fig.4C $\mathrm{C}_{1}$ and $\mathrm{C}_{2}$ ). Nuclear morphology was also visualized by Hoechst 33342 staining. Under normal conditions, nuclei appeared relatively large and faintly stained, while after $8 \mathrm{~h}$ oxygen-glucose deprivation followed by $3 \mathrm{~h}$ reoxygenation, the nuclei looked condensed, fragmented and heterogeneous (Fig.5 $\mathrm{A}_{1}$ and $\mathrm{A}_{2}$ ). TUNEL staining showed that OGD/R HK-2 cells had significantly increased numbers of TUNEL-positive cells, and that NADPH treatment significantly reduced the TUNEL-positive population (Fig.5 $\mathrm{B}_{1}$ and $\mathrm{B}_{2}$ ). These results suggested that NADPH provided renal protection through its anti-apoptotic effects.

\section{NADPH Suppresses NF- $\kappa B$ Activity In vivo and In vitro}

$\mathrm{NF}-\kappa \mathrm{B}$ is an essential transcriptional factor that is involved in inflammatory processes. Thus, we analyzed the effects of NADPH on the NF- $\kappa B$ pathway. Western blotting was performed to detect the level of IкB- $\alpha$ and Cox-2. Compared with the sham group, Cox- 2 expression in the model group was markedly increased (Fig.6 $\mathrm{A}_{1}$ and $\mathrm{A}_{2}$ ), and IкB- $\alpha$ expression in the model group was decreased, which implied activation of NF-kB (Fig.6 $\mathrm{B}_{1}$ and $\mathrm{B}_{2}$ ). Both phenotypes were reversed by NADPH treatment. Immunofluorescence was used to analyze the nuclear translocation of NF- $\mathrm{kB}$ in HK-2 cells. As shown in Fig. 6C, while p65 was concentrated in the nucleus of $8 \mathrm{~h}$ oxygen-glucose deprivation and $3 \mathrm{~h}$ reoxygenated cells, p65 was found in the nuclei of untreated cells (Fig. $6 \mathrm{C}_{1}$ ). As expected, the nuclear translocation of p65 was blocked in NADPH-treated cells.

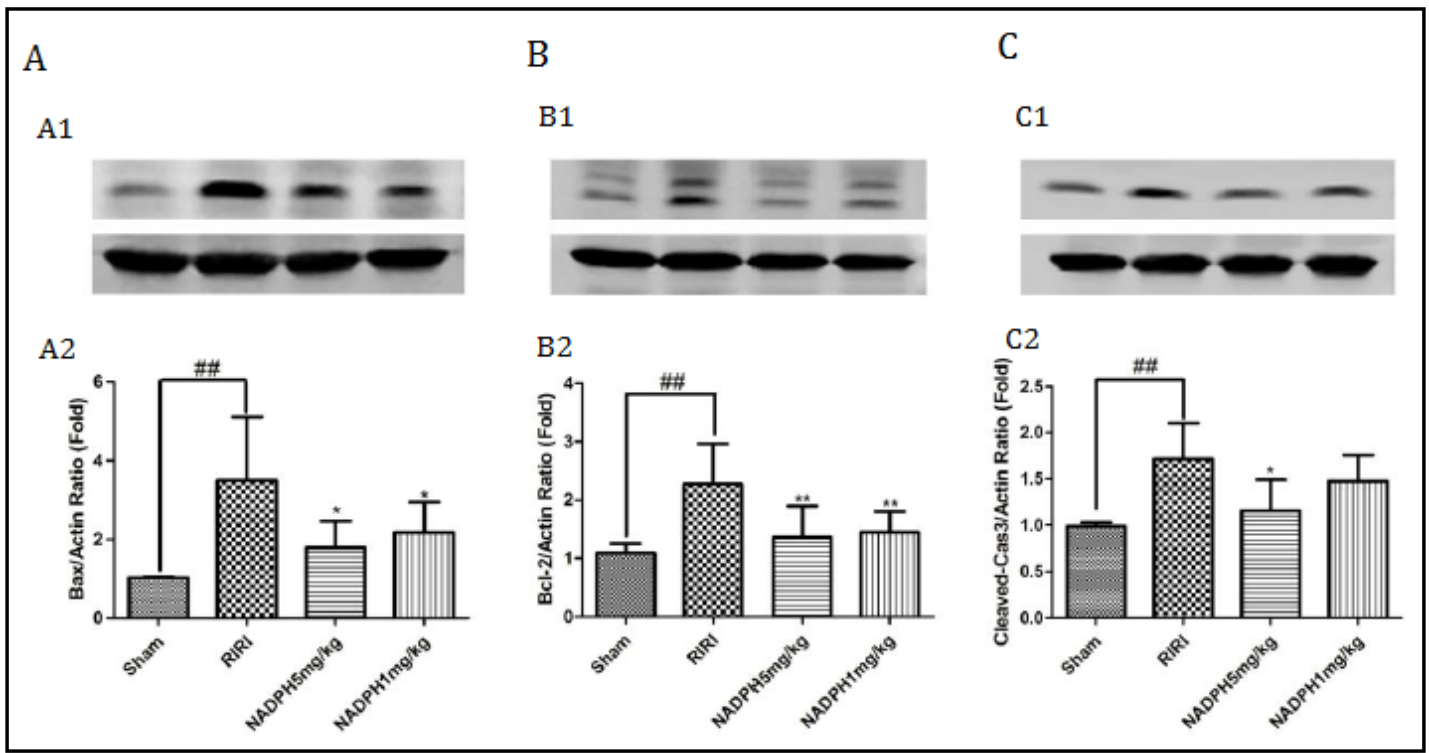

Fig. 4. NADPH Inhibits Apoptosis In Vivo. Mice in the different groups received different treatments, and kidneys were collected $24 \mathrm{~h}$ after reperfusion and subjected to western blot analysis. NADPH treatment reduced $B a x\left(A_{1}\right.$ and $\left.A_{2}\right)$, Bcl-2 $\left(B_{1}\right.$ and $\left.B_{2}\right)$ and cleaved Caspase- $3\left(C_{1}\right.$ and $\left.C_{2}\right)$ levels. Bar represents mean $\pm S D$; $\mathrm{n}=5$ independent experiments; ${ }^{\# \#} \mathrm{p}<0.01$ vs the Sham group; ${ }^{* *} \mathrm{p}<0.01,{ }^{*} \mathrm{p}<0.05$ vs the RIRI group. 


\section{Kidney Blood Pressure Research}

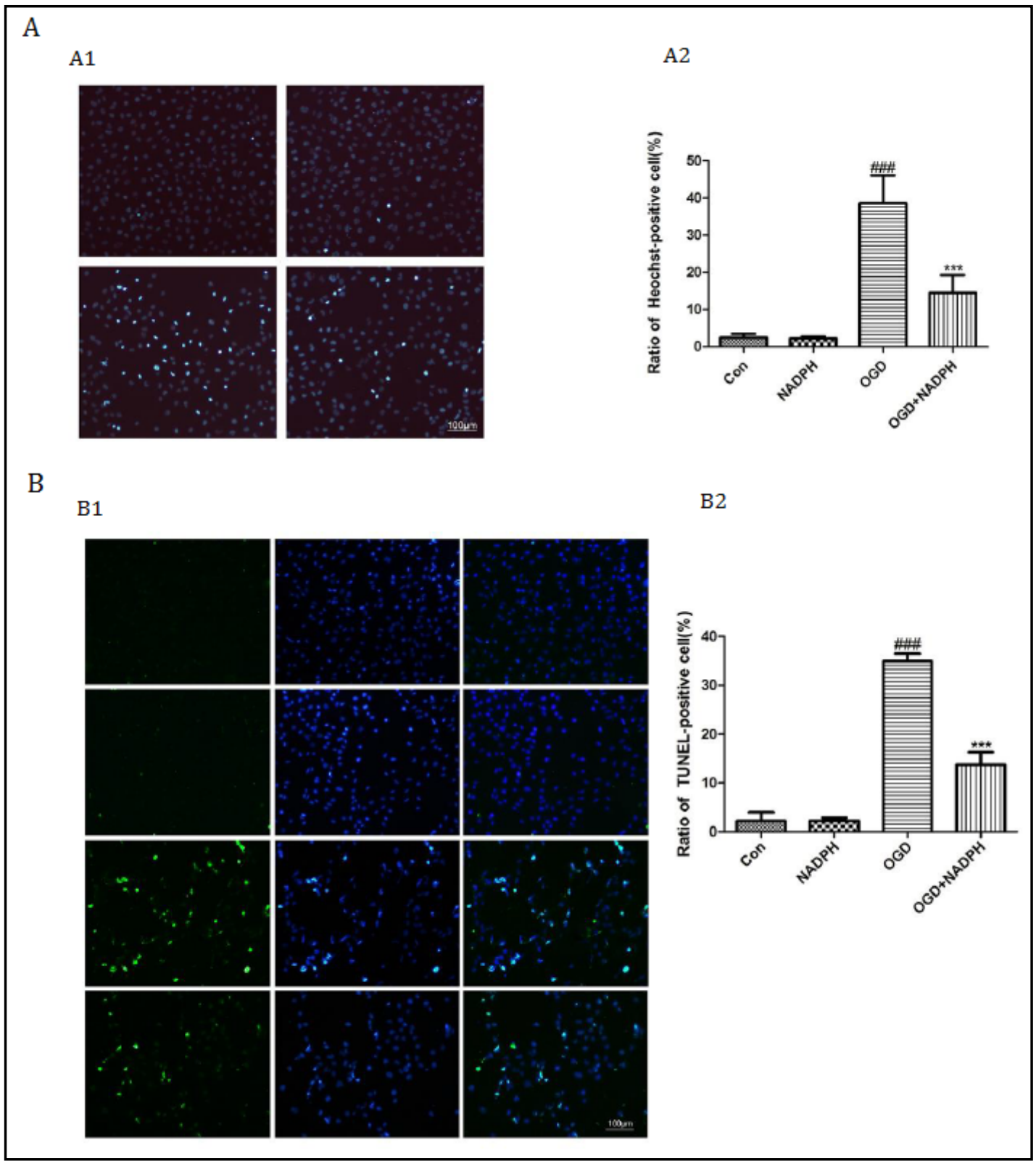

Fig. 5. NADPH Inhibits Apoptosis In Vitro. HK-2 cells received the indicated doses of NADPH with or without oxygen-glucose deprivation. Cells were subjected to oxygen-glucose deprivation for $8 \mathrm{~h}$, representative Hoechst-stained images $\left(A_{1}\right)$ and the ratio of Hoechst-positive cells $\left(A_{2}\right)$, and representative TUNEL-stained images $\left(B_{1}\right)$ and the ratio of TUNEL-positive cells $\left(B_{2}\right)$ showed the level of apoptosis in HK-2 cells $3 \mathrm{~h}$ after reperfusion. Scale bar: $100 \mu \mathrm{m} ; \mathrm{n}=3$ independent experiments. ${ }^{\# \#} \mathrm{p}<0.001$ vs the control group; ${ }^{* * *} \mathrm{p}<0.001$ vs the oxygen-glucose deprivation control group. 


\section{Kidney \\ Blood Pressure \\ Research}

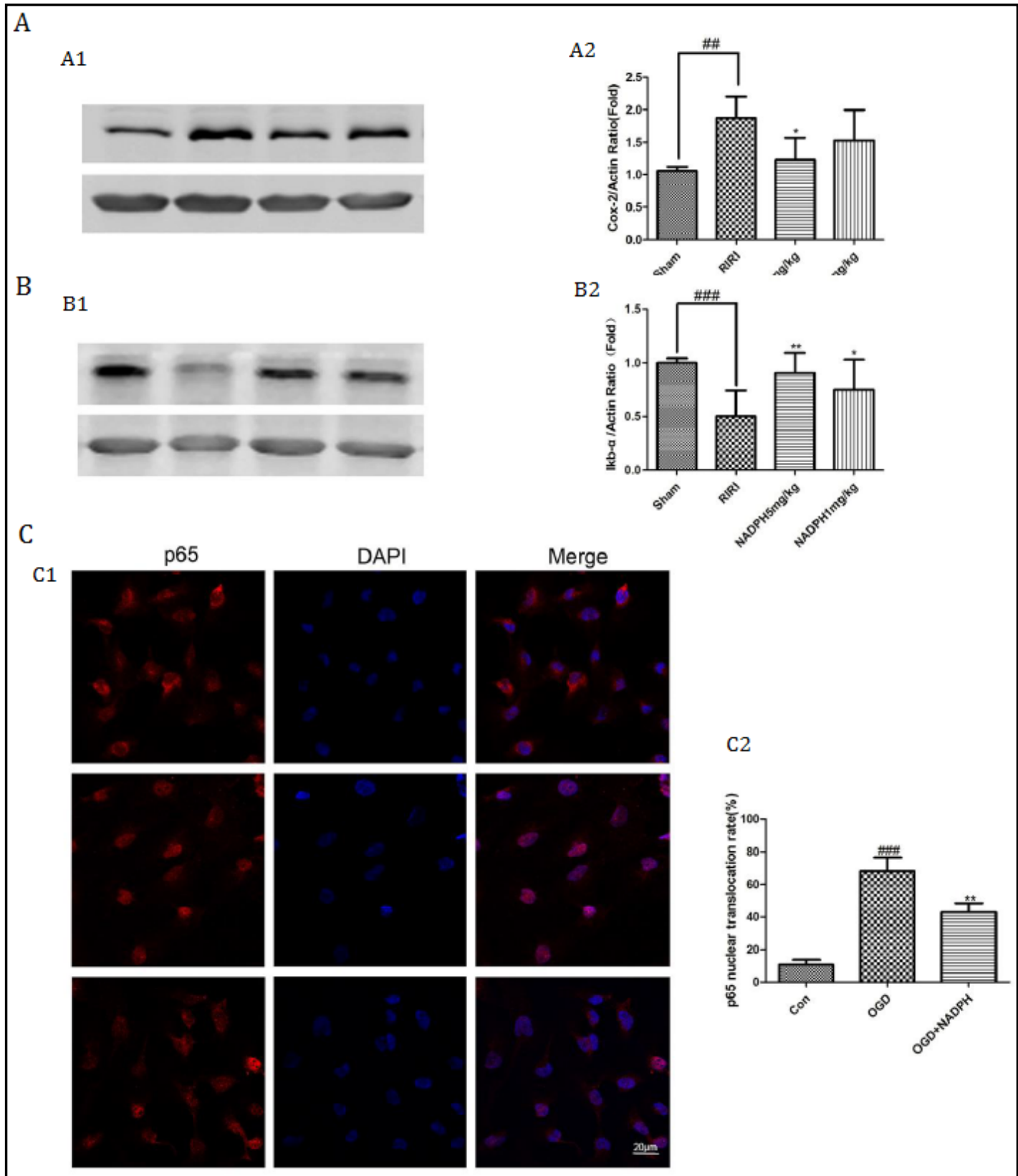

Fig. 6. NADPH Suppresses NF- $\kappa B$ Activity. Mice in the different groups received different treatments, and kidneys were collected $24 \mathrm{~h}$ after reperfusion and subjected to western blot analysis. NADPH treatment reduced Cox-2 expression $\left(A_{1}\right.$ and $\left.A_{2}\right)$ and increased $I \kappa B-\alpha$ expression $\left(B_{1}\right.$ and $\left.B_{2}\right)$. Bar represents mean $\pm S D$; $\mathrm{n}=5$ independent experiments; ${ }^{\# \#} \mathrm{p}<0.001,{ }^{\# \#} \mathrm{p}<0.01$ vs the Sham group; ${ }^{* *} \mathrm{p}<0.01,{ }^{*} \mathrm{p}<0.05$ vs the RIRI group. HK-2 cells received the indicated doses of NADPH with or without oxygen-glucose deprivation. Cells were subject to oxygen-glucose deprivation for $8 \mathrm{~h}$, and nuclear and cytosolic p65 (red) were detected by immunofluorescence; nuclei were stained with DAPI $\left(\mathrm{C}_{1}\right)$. The p65 nuclear translocation rate was blocked in NADPH-treatment cells $\left(C_{2}\right)$. Scale bar: $20 \mu \mathrm{m} ; \mathrm{n}=3$ independent experiments. ${ }^{\# \#} \mathrm{p}<0.001$ vs the control group; ${ }^{* *} \mathrm{p}<0.01$ vs the oxygen-glucose deprivation control group. 


\section{Kidney Blood Pressure Research}

Kidney Blood Press Res 2018;43:651-663

\begin{tabular}{l|l}
\hline DOI: $10.1159 / 000489620$ & (C) 2018 The Author(s). Published by S. Karger AG, Basel
\end{tabular}

Published onlıne: 8 May, 2018

www.karger.com/kbr

Weng et al.: Protective Effect of NAPDH on Renal IRI

Discussion

For decades, it has been observed that the renal IRI is a form of clinical kidney defect that can lead to acute renal failure [22,23]. However, due to its complexity and multiplicity of pathogenesis, there is still no proven process to treat this disease, and mortality from the disease remains prevalent [24]. In this study, we evaluated the effects of NADPH on renal IRI both for in vivo renal I/R and OGD/R cells in vitro. Based on our results, NADPH supplementation enhanced renal function as seen by decreased levels of the renal injury, and that histological indices of injury were improved. These results showed that NADPH has protective potency against renal IRI in vivo. Using NADPH dramatically reduced cell injury and histological damage, showing that NADPH also has protective functions in vitro. In this study, we found that NADPH provides this activity by reducing oxidative stress, apoptosis, and blocking NF- $\kappa \mathrm{B}$ signaling.

Ischemia is always associated with oxidative stress, which can cause DNA damage [25, 26], sugar fragmentation and base oxidation [27]. Oxidative stress is known to result from an imbalance between ROS production and antioxidants and repair processes. ROS-mediated lipid peroxidation is often believed to be an important cause of damage and destruction to cell membranes during oxidative stress [28]. MDA results from lipid peroxidation and is generally employed as a biomarker of oxidative stress [29-31]. GSH is the main safeguard against oxidative damage by promoting the cellular system of protection against oxidative damage [32]. One related study showed that Vitamin C intake increased GSH levels after renal ischemia injury [33]. GSH, along with glutathione peroxidase, acts with hydrogen peroxide to block the peroxidation chain reaction and defend protein thiol groups from nonenzymatic oxidation [34]. The findings of Kim et al. suggested that G6PD, GSH, ROS, and NADPH were elevated after renal IRI, and that high NADPH may scavenge ROS through GSH [15]. Earlier studies have indicated that NADPH has both long- and short-term therapeutic effects when employed in two rodent stroke groups. The use of NADPH dramatically raised ATP and reduced glutathione levels, and decreased ROS levels [17]. Our study showed that NADPH treatment reduced oxidative stress in renal IRI, which was reflected by changes in GSH and MDA levels in kidney tissues and DHE staining in oxygen-glucose deprivation/ reperfusion cells. One possible explanation for these findings is that NADPH may scavenge ROS by preserving GSH levels.

Inflammation is also a major contributor to the pathogenesis of renal ischemia injury [24]. NF- $\kappa \mathrm{B}$ is a protein complex that acts as a trans-activator of genes involved in inflammation, and thus regulates inflammatory responses [6]. The presence of antigens and pro-inflammatory cytokines may lead to activation of the IKK complex, which further produces phospho-I $\mathrm{B}$ proteins. In the cytoplasm, NF- $\kappa \mathrm{B} /$ Rel proteins are blocked and bound by $\mathrm{I} \kappa \mathrm{B}$, but phosphorylation releases the NF- $\kappa \mathrm{B} / \mathrm{Rel}$ complexes to translocate into the nucleus and drive the expression of target genes that cause inflammation, including Cox2, which works as an pro-inflammatory transcription factor that has been proven to be relevant to IRI [21]. Zhao et al. showed that eliminating NF- $\kappa B$ activation through interactions with the P65 subunit prevents the onset of inflammation in renal IRI [6, 35, 36]. Moreover, antioxidants and anti-oxidant enzymes can inhibit NF- $\mathrm{\kappa B}$ activation by lowering intracellular ROS accumulation [6,37]. Our data indicated that renal IRI-induced activation of NF- $\kappa B$ was significantly suppressed by NADPH. Additionally, NADPH administration inhibited increased levels of pro-inflammatory target genes of NF- $\mathrm{kB}$, such as Cox2. In conclusion, NADPH reduces inflammation during renal IRI by inhibiting NF- $\kappa B$ signaling.

Oxidative stress may lead to apoptosis, which has been shown to participate in induced IRI[38-40]. In the kidneys, the link between apoptosis inhibition and improved renal function is not obvious. It is known that Bax activation and $\mathrm{Bcl}-2$ downregulation play important roles in the apoptotic cascade [31], and that Caspase-3 activation promotes apoptosis [27]. A previous study proposed that apoptosis is proinflammatory, and detrimental to renal function [41]. In this study, renal IRI increased the levels of Bcl-2, Bax and cleaved Caspase3, 


\section{Kidney Blood Pressure Research}

while NADPH treatment reduced these phenotypes. A similar observation was found in that Bcl-2 and Bax were mainly localized in renal tubular cells, and that levels of Bcl-2 and Bax were remarkably increased in IRI kidneys compared with the sham group [42]. However, $\mathrm{Na}$ et al. observed that Bax expression was significantly elevated, and that Bcl- 2 expression was decreased in IR kidney [24]. The various ischemia time, mouse strains, and operative approaches may cause these different findings. Based on our data, we observed that the upregulation of Bcl-2 in IRI kidney can be used to prevent IR-induced apoptosis. Supplying exogenous NADPH may defend kidney tissues from potential ischemia/reperfusion damage by inhibiting apoptotic pathways, as evidenced by the decreased levels of Bax and cleaved Caspase-3. Additionally, fewer apoptotic morphological changes were found in the NADPH treatment group than the control group after TUNEL staining. Apoptosis can be activated through the pro-apoptotic protein Bax and blocked by the anti-apoptotic protein Bcl-2. However, we showed that renal IRI raised both Bcl-2 and Bax expression. In the future we will conduct further studies to examine the link between Bcl-2 and Bax in relation to renal IRI.

\section{Conclusion}

The findings of this study suggest that NADPH treatment may attenuate renal IRI by reducing ROS production, suppressing NF- $\mathrm{BB}$ activity and inhibiting apoptosis. As a result, NADPH might be a promising drug that can be translated into clinical use to treat renal IRI. However, there are flaws in this study. There is no single animal model that can completely mimic the pathology of human renal IRI. Multiple animal models should be used to evaluate the therapeutic effects of NADPH. Also, compared with what was described to be the underlying mechanisms, actual clinical situations are more complex. It is also possible that other mechanisms may have influenced the NADPH treatment group, yet these variables remain to be determined. Previous studies have also found that NADPH inhibited platelet aggregation in MCAO and pMCAO models [17], which suggested that NADPH could improve blood supply to the ischemic hemisphere. Further research is required to address these abovementioned flaws and remaining questions.

\section{Acknowledgements}

This work was founded by the Natural Science Foundation of China (30930035 and 81271459), a "973" project from the Ministry of Science and Technology of China (2011CB51000), the Priority Academic Program Development of Jiangsu Higher Education Institutes (PAPD) and the Graduate Education Innovation Project of Jiangsu Province (CXZZ12_0850).

Yan Xie and Zheng-hong Qin designed the research plan, gave study suggestions and reviewed and revised the manuscript; Xiao-fen Weng carried out the experimental studies and wrote the manuscript. Song-tao Li, Qi Song, Qi Zhu, Dan-dan Song, partially performed some experiments. Xiao-fen Weng and Yan Xie analyzed data. All authors have read and approved the final manuscript.

\section{Disclosure Statement}

The authors declare they have no conflicts of interest regarding the publication of this article. 


\section{Kidney \\ Blood Pressure Research}

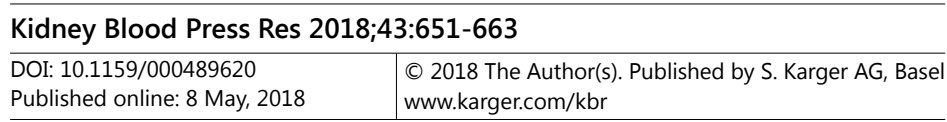

Weng et al.: Protective Effect of NAPDH on Renal IRI

\section{References}

-1 Hesketh EE, Czopek A, Clay M, Borthwick G, Ferenbach D, Kluth D, Hughes J: Renal ischaemia reperfusion injury: a mouse model of injury and regeneration. J Vis Exp 2014; DOI:10.3791/51816.

-2 Sheashaa H, Lotfy A, Elhusseini F, Aziz AA, Baiomy A, Awad S, Alsayed A, El-Gilany AH, Saad MA, Mahmoud K, Zahran F, Salem DA, Sarhan A, Ghaffar HA, Sobh M: Protective effect of adipose-derived mesenchymal stem cells against acute kidney injury induced by ischemia-reperfusion in Sprague-Dawley rats. Exp Ther Med 2016;11:1573-1580.

3 Malek M, Nematbakhsh M: Renal ischemia/reperfusion injury; from pathophysiology to treatment. J Renal Inj Prev 2015;4:20-27.

-4 Kelly KJ, Plotkin Z, Dagher PC: Guanosine supplementation reduces apoptosis and protects renal function in the setting of ischemic injury. Journal of Clinical Investigation 2001;108:1291-1298.

5 Marko L, Vigolo E, Hinze C, Park JK, Roel G, Balogh A, Choi M, Wubken A, Cording J, Blasig IE, Luft FC, Scheidereit C, Schmidt-Ott KM, Schmidt-Ullrich R, Muller DN: Tubular Epithelial NF-kappaB Activity Regulates Ischemic AKI. J Am Soc Nephrol 2016;27:2658-2669.

6 Zhao L, Xu L, Tao X, Han X, Yin L, Qi Y, Peng J: Protective Effect of the Total Flavonoids from Rosa laevigata Michx Fruit on Renal Ischemia-Reperfusion Injury through Suppression of Oxidative Stress and Inflammation. Molecules 2016; DOI: 10.3390/molecules21070952.

7 Li G, Zhang HX, Wang YP, Zhang J, Hong K, Tian XJ, Ma LL: [Protective effect of phloroglucinol on renal ischemia and reperfusion injury]. Beijing Da Xue Xue Bao 2015;47:743-748.

-8 Choi EK, Jung H, Kwak KH, Yi SJ, Lim JA, Park SH, Park JM, Kim S, Jee DL, Lim DG: Inhibition of Oxidative Stress in Renal Ischemia-Reperfusion Injury. Anesth Analg 2017;124:204-213.

-9 Tan J, Hu J, He Y, Cui F: Protective role of silymarin in a mouse model of renal Ischemia-Reperfusion injury. Diagn Pathol 2015;10:198.

10 Zahran MH, Hussein AM, Barakat N, Awadalla A, Khater S, Harraz A, Shokeir AA: Sildenafil activates antioxidant and antiapoptotic genes and inhibits proinflammatory cytokine genes in a rat model of renal ischemia/reperfusion injury. Int Urol Nephrol 2015;47:1907-1915.

-11 Chen H, Wang L, Xing BZ, Liu XH, Chen ZY, Weng XD, Qiu T, Liu L: Ischemic postconditioning attenuates inflammation in rats following renal ischemia and reperfusion injury. Exp Ther Med 2015;10:513-518.

12 Hu S, Zhang Y, Zhang M, Guo Y, Yang P, Zhang S, Simsekyilmaz S, Xu JF, Li J, Xiang X, Yu Q, Wang CY: Aloperine protects mice against ischemia reperfusion (IR)-induced renal injury by regulating PI3K/AKT/mTOR signaling and AP-1 activity. Mol Med 2015; DOI:10.2119/molmed.2015.00056.

13 Liu YE, Tong CC, Zhang YB, Jin HX, Gao Y, Hou MX: Effect of dexmedetomidine on rats with renal ischemiareperfusion injury and the expression of tight junction protein in kidney. Int J Clin Exp Med 2015;8:1875118757.

14 Bensaad K, Tsuruta A, Selak MA, Vidal MN, Nakano K, Bartrons R, Gottlieb E, Vousden KH: TIGAR, a p53inducible regulator of glycolysis and apoptosis. Cell 2006;126:107-120.

15 Kim J, Devalaraja-Narashimha K, Padanilam BJ: TIGAR regulates glycolysis in ischemic kidney proximal tubules. Am J Physiol Renal Physiol 2015;308:F298-308.

16 Li M, Sun M, Cao L, Gu JH, Ge J, Chen J, Han R, Qin YY, Zhou ZP, Ding Y, Qin ZH: A TIGAR-regulated metabolic pathway is critical for protection of brain ischemia. J Neurosci 2014;34:7458-7471.

-17 Li M, Zhou ZP, Sun M, Cao L, Chen J, Qin YY, Gu JH, Han F, Sheng R, Wu JC, Ding Y, Qin ZH: Reduced Nicotinamide Adenine Dinucleotide Phosphate, a Pentose Phosphate Pathway Product, Might Be a Novel Drug Candidate for Ischemic Stroke. Stroke 2016;47:187-195.

-18 Cao L, Chen J, Li M, Qin YY, Sun M, Sheng R, Han F, Wang G, Qin ZH: Endogenous level of TIGAR in brain is associated with vulnerability of neurons to ischemic injury. Neurosci Bull 2015;31:527-540.

19 Jeon SM, Chandel NS, Hay N: AMPK regulates NADPH homeostasis to promote tumour cell survival during energy stress. Nature 2012;485:661-665.

20 Tan SX, Teo M, Lam YT, Dawes IW, Perrone GG: Cu, Zn superoxide dismutase and NADP(H) homeostasis are required for tolerance of endoplasmic reticulum stress in Saccharomyces cerevisiae. Mol Biol Cell 2009;20:1493-1508. 


\section{Kidney \\ Blood Pressure Research}

\begin{tabular}{|c|c|}
\hline Kidney Blood Press Re & 51-663 \\
\hline $\begin{array}{l}\text { DOI: } 10.1159 / 000489620 \\
\text { Publisned onlIne: } 8 \text { IVay, } 2018\end{array}$ & $\begin{array}{l}\text { ( ) } 2018 \text { The Author(s). Published by S. Karger AG, Basel } \\
\text { www.karger.com/kbr }\end{array}$ \\
\hline
\end{tabular}

Weng et al.: Protective Effect of NAPDH on Renal IRI

-21 Zhu Q, Huang J, Wang SZ, Qin ZH, Lin F: Cobrotoxin extracted from Naja atra venom relieves arthritis symptoms through anti-inflammation and immunosuppression effects in rat arthritis model. J Ethnopharmacol 2016;194:1087-1095.

-22 Rongen GA: High Dose Meclizine Prevents Renal Ischemia-Reperfusion Injury in Healthy Male Mice. EBioMedicine 2015;2:1012-1013.

-23 Xie DQ Sun GY, Zhang XG, Gan H: Osthole Preconditioning Protects Rats Against Renal IschemiaReperfusion Injury. Transplant Proc 2015;47:1620-1626.

-24 Na KR, Choi H, Jeong JY, Lee KW, Chang YK, Choi DE: Nafamostat Mesilate Attenuates Ischemia-ReperfusionInduced Renal Injury. Transplant Proc 2016;48:2192-2199.

25 Xie JM, Li B, Yu HP, Gao QG, Li W, Wu HR, Qin ZH: TIGAR has a dual role in cancer cell survival through regulating apoptosis and autophagy. Cancer Res 2014;74:5127-5138.

26 Zhang G, Zou X, Miao S, Chen J, Du T, Zhong L, Ju G, Liu G, Zhu Y: The anti-oxidative role of micro-vesicles derived from human Wharton-Jelly mesenchymal stromal cells through NOX2/gp91(phox) suppression in alleviating renal ischemia-reperfusion injury in rats. PLoS One 2014;9:e92129.

-27 Zhou JH, Zhang TT, Song DD, Xia YF, Qin ZH, Sheng R: TIGAR contributes to ischemic tolerance induced by cerebral preconditioning through scavenging of reactive oxygen species and inhibition of apoptosis. Sci Rep 2016;6:27096.

28 Mintzer JE, Lewis L, Pennypacker L, Pitner J, Simpson W, Bachman D, Wohlreich GM, Meeks A, Hunt S, Herman K, et al.: A new approach for the management of acute psychiatric disorders in elderly demented patients. J S C Med Assoc 1994;90:373-376.

-29 Sahna E, Parlakpinar H, Turkoz Y, Acet A: Protective effects of melatonin on myocardial ischemia/ reperfusion induced infarct size and oxidative changes. Physiol Res 2005;54:491-495.

-30 Jakesevic M, Aaby K, Borge GI, Jeppsson B, Ahrne S, Molin G: Antioxidative protection of dietary bilberry, chokeberry and Lactobacillus plantarum HEAL19 in mice subjected to intestinal oxidative stress by ischemia-reperfusion. BMC Complement Altern Med 2011;11:8.

31 Xie D, Xu Y, Jing W, Juxiang Z, Hailun L, Yu H, Zheng DH, Lin YT: Berberine nanoparticles protects tubular epithelial cells from renal ischemia-reperfusion injury. Oncotarget 2017;8:24154-24162.

32 Kinaci MK, Erkasap N, Kucuk A, Koken T, Tosun M: Effects of quercetin on apoptosis, NF-kappaB and NOS gene expression in renal ischemia/reperfusion injury. Exp Ther Med 2012;3:249-254.

-33 Zhu YB, Zhang YP, Zhang J, Zhang YB: Evaluation of Vitamin C Supplementation on Kidney Function and Vascular Reactivity Following Renal Ischemic Injury in Mice. Kidney Blood Press Res 2016;41:460-470.

34 Szaroma W, Dziubek K, Kapusta E: Effect of N-methyl-D-aspartic acid on activity of superoxide dismutase, catalase, glutathione peroxidase and reduced glutathione level in selected organs of the mouse. Acta Physiol Hung 2014;101:377-387.

35 Rusai K, Sollinger D, Baumann M, Wagner B, Strobl M, Schmaderer C, Roos M, Kirschning C, Heemann U, Lutz J: Toll-like receptors 2 and 4 in renal ischemia/reperfusion injury. Pediatr Nephrol 2010;25:853-860.

-36 Cao CC, Ding XQ, Ou ZL, Liu CF, Li P, Wang L, Zhu CF: In vivo transfection of NF-kappaB decoy oligodeoxynucleotides attenuate renal ischemia/reperfusion injury in rats. Kidney Int 2004;65:834-845.

-37 Dorai T, Fishman AI, Ding C, Batinic-Haberle I, Goldfarb DS, Grasso M: Amelioration of renal ischemiareperfusion injury with a novel protective cocktail. J Urol 2011;186:2448-2454.

38 Qiu X, Fu K, Zhao X, Zhang Y, Yuan Y, Zhang S, Gu X, Guo H: Protective effects of astaxanthin against ischemia/reperfusion induced renal injury in mice. J Transl Med 2015;13:28.

39 Wang L, Liu X, Chen H, Chen Z, Weng X, Qiu T, Liu L: Effect of picroside II on apoptosis induced by renal ischemia/reperfusion injury in rats. Exp Ther Med 2015;9:817-822.

40 Nie H, Xue X, Li J, Liu X, Lv S, Guan G, Liu H, Liu G, Liu S, Chen Z: Nitro-oleic acid attenuates OGD/R-triggered apoptosis in renal tubular cells via inhibition of Bax mitochondrial translocation in a PPAR-gammadependent manner. Cell Physiol Biochem 2015;35:1201-1218.

-41 Daemen MA, van 't Veer C, Denecker G, Heemskerk VH, Wolfs TG, Clauss M, Vandenabeele P, Buurman WA: Inhibition of apoptosis induced by ischemia-reperfusion prevents inflammation. J Clin Invest 1999;104:541-549.

42 Chang YK, Choi DE, Na KR, Lee SJ, Suh KS, Kim SY, Shin YT, Lee KW: Erythropoietin attenuates renal injury in an experimental model of rat unilateral ureteral obstruction via anti-inflammatory and anti-apoptotic effects. J Urol 2009;181:1434-1443. 